\title{
The effect of ketamine on the incidence of emergence agitation in children undergoing tonsillectomy and adenoidectomy under sevoflurane general anesthesia
}

\author{
Yoon Sook Lee, Woon Young Kim, Jae Ho Choi, Joo Hyung Son, Jae Hwan Kim, and Young Cheol Park \\ Department of Anesthesiology and Pain Medicine, Ansan Hospital, Korea University College of Medicine, Ansan, Korea
}

Background: The rapid emergence and recovery from general anesthesia afforded by sevoflurane is associated with a high incidence of emergence agitation in children. Small doses of ketamine reduce the incidence of emergence agitation. This study compared the effects of ketamine $0.25 \mathrm{mg} / \mathrm{kg}$ and $0.5 \mathrm{mg} / \mathrm{kg}$ on emergence agitation and postoperative pain.

Methods: The effects of added intravenous ketamine were evaluated in 93 children, ASA I-II, 2-14 years old, undergoing an adenotonsillectomy. The patients were allocated randomly to one of three groups receiving saline (group C), ketamine $0.25 \mathrm{mg} / \mathrm{kg}$ (group K0.25) or ketamine $0.5 \mathrm{mg} / \mathrm{kg}$ (group K0.5). The children in each group were administered the study drugs 10 minutes before the end of surgery. The recovery characteristics, including the time to extubation, delivery time from the PACU, postoperative nausea and vomiting, agitation and pain were assessed.

Results: There were no significant differences in the extubation time, delivery time and postoperative nausea and vomiting between the three groups. There were significant differences in modified CHEOPS (Children's Hospital of Eastern Ontario Pain Scale) between the three groups. The incidence of emergence agitation was low in the K0.25 and K0.5 groups compared to the control group. However, there was no significant difference between the K0.25 and K0.5 groups.

Conclusions: There was no significant difference in the incidence of emergence agitation between K0.25 and K0.5 groups. However, K0.5 group showed a lower pain score than K0.25 group. (Korean J Anesthesiol 2010; 58: 440-445)

Key Words: Emergence agitation, Ketamine, Sevoflurane.

Received: February 3, 2010. Revised: February 24, 2010. Accepted: March 12, 2010.

Corresponding author: Woon Young Kim, M.D., Ph.D., Department of Anesthesiology and Pain Medicine, Ansan Hospital, Korea University College of Medicine, 516, Kojan-1dong, Ansan 425-707, Korea. Tel: 82-31-412-5291, Fax: 82-31-412-5294, E-mail: ckssis@korea.ac.kr (c) This is an open-access article distributed under the terms of the Creative Commons Attribution Non-Commercial License (http:// creativecommons.org/licenses/by-nc/3.0/), which permits unrestricted non-commercial use, distribution, and reproduction in any medium, provided the original work is properly cited. 


\section{Introduction}

Sevoflurane is an inhalation anesthetic agent used frequently to induce and maintain outpatient or pediatric anesthesia due to its excellence in hemodynamic stability, less irritation of the mucous membranes and low blood solubility, which causes rapid induction and emergence from anesthesia and controls the anesthesia depth $[1,2]$. However, it has been reported that there are risks with emergence agitation, the incidence rate of which is particularly high in children, ranging from 30 to $80 \%$ of those undergoing general anesthesia with sevoflurane. There have been many studies on the causes of emergence agitation and/or the preventive effects against emergence agitation, but the pathogenesis and preventive treatments are not completely understood.

Ketamine is an effective drug for sedation, analgesia and amnesia. Kararmaz et al. [3] administered $6 \mathrm{mg} / \mathrm{kg}$ ketamine orally as preoperative medication to patients and reported a decrease in the incidence of emergence agitation without a delay in recovery. The effect of ketamine on decreasing the incidence of emergence agitation was confirmed by AbuShahwan et al. [4], who injected $0.25 \mathrm{mg} / \mathrm{kg}$ ketamine intravenously 10 minutes before the completion of surgery.

Following these studies, in this study, two different doses of ketamine, $0.25 \mathrm{mg} / \mathrm{kg}$ and $0.5 \mathrm{mg} / \mathrm{kg}$, was administered 10 minutes before the end of surgery, and the development of emergence agitation, postoperative pain intensity, effects on recovery and incidence of side-effects were compared.

\section{Materials and Methods}

The institutional review board approved this study and the patient's guardians provided informed consent after giving a full explanation of the purpose and procedure of this study. Ninety three children, aged between 2-14 years, with American Society of Anesthesiologists (ASA) physical status I-II, who were scheduled to undergo an adenotonsillectomy (or adenoidectomy) under general anesthesia, were enrolled this study. Children with cognitive or developmental disorders were excluded.

The patients were allocated randomly to one of three groups: the control group (administered with a saline solution $10 \mathrm{~min}$ before the end of surgery, $\mathrm{n}=31$ ), K0.25 group (administered with $0.25 \mathrm{mg} / \mathrm{kg}$ of ketamine $10 \mathrm{~min}$ before the end of operation, $\mathrm{n}=31$ ), and K0.5 group (administered with $0.5 \mathrm{mg} / \mathrm{kg}$ of ketamine $10 \mathrm{~min}$ before the end of surgery, $\mathrm{n}=31$ ). There were no significant differences in age, gender, height, weight, American Society of Anesthesiologists physical status and the length of anesthesia and operation between the three groups (Table 1).

Atropine $0.01 \mathrm{mg} / \mathrm{kg}$ as a premedication was injected intramuscularly $30 \mathrm{~min}$ before the induction of anesthesia. Upon the patients' arrival into the operating room, the blood pressure, electrocardiogram and pulse oximetry were monitored. Thiopental sodium $5 \mathrm{mg} / \mathrm{kg}$ and rocuronium $0.6 \mathrm{mg} / \mathrm{kg}$ were administered intravenously, and endotracheal intubation was performed. Anesthesia was maintained with oxygen $1.5 \mathrm{~L} /$ min, nitrous oxide $1.5 \mathrm{~L} / \mathrm{min}$ and sevoflurane at $1.5-3.0 \mathrm{vol} \%$, while controlled ventilation was performed to sustain the endtidal carbon dioxide (ETCO2) between 30 and $35 \mathrm{mmHg}$. Ten minutes before the end of surgery, the experimental drugs were administered by physicians not participating in the anesthesia, $5 \mathrm{ml}$ in total. The removal time of the mouth gag defined the termination of surgery. At the end of surgery, the administration of sevoflurane and nitrous oxide was discontinued, and manual ventilation was then performed with $100 \%$ oxygen at $6 \mathrm{~L} / \mathrm{min}$. Pyridostigmine $0.2 \mathrm{mg} / \mathrm{kg}$ and glycopyrrolate $0.008 \mathrm{mg} / \mathrm{kg}$ were administered to reverse the residual muscle relaxation. Extubation was performed when the patients' gag reflex was restored and they showed facial grimaces or purposefulappearing motor movements, and the time period from the end of surgery to the extubation time was recorded. The time span from the attachment of the basic monitoring system until the extubation time was recorded as the duration of anesthesia, whereas the time span between the insertion and removal of the cheek distender was recorded as the duration of surgery. Upon extubation, the patients were transferred to the postanesthesia care unit (PACU), where their emergence agitation

Table 1. Demographic Data

\begin{tabular}{|c|c|c|c|}
\hline Group & $C(\mathrm{n}=30)$ & $\mathrm{K} 0.25(\mathrm{n}=30)$ & $\mathrm{K} 0.5(\mathrm{n}=30)$ \\
\hline Age (years) & $7.00(5.06,9.15)$ & $6.08(5.08,7.10)$ & $6.58(5.67,8.58)$ \\
\hline $\operatorname{Sex}(M: F)$ & $20: 10$ & $17: 13$ & $18: 12$ \\
\hline Height (cm) & $123.20(109.88,135.35)$ & $115.00(109.75,120.25)$ & $118.00(113.58,127.75)$ \\
\hline Weight (kg) & $26.15(18.34,39.05)$ & $22.00(19.04,25.85)$ & $21.75(19.50,30.99)$ \\
\hline ASA (I : II) & $30: 0$ & $30: 0$ & $28: 2$ \\
\hline Duration of anesthesia (min) & $55.00(50.00,65.00)$ & $60.00(48.75,70.00)$ & $60.00(50.00,75.00)$ \\
\hline Duration of operation (min) & $34.00(22.00,40.00)$ & $32.50(24.75,45.50)$ & $35.00(25.00,50.75)$ \\
\hline
\end{tabular}

Values are median (25\%, 75\%). There are no significant differences among the three groups. 
was observed by nurses who were blinded to the patients' groups. Emergence agitation was assessed using a simple fourpoint scale as follows: 1 , asleep; 2 , awake but calm; 3 , agitated but consolable; and 4, severely agitated and difficult to console. Upon admission to the PACU and at every five minutes, the patients' emergence behavior was measured and the highest score was recorded during the PACU stay.

The level of nausea was evaluated using a four-point scale to check for the incidence of adverse events as follows: 1 , none; 2 , nausea only; 3 , one episode of vomiting; and 4 , more than 2 episodes of vomiting. Recurrent vomiting within 5 minutes was considered to be one single episode. Ondansetron $0.15 \mathrm{mg} /$ $\mathrm{kg}$ was provided as an antiemetic drug. If the vomiting was not controlled, repeated administration was performed until the total dose reached $4 \mathrm{mg}$.

Postoperative pain was assessed using the modified Children's Hospital of Eastern Ontario Pain Scale (CHEOPS) and measured upon admission to the PACU, and then pain was measured every five minutes until the time of discharge from the PACU. During the PACU stay, the highest score at any time was recorded.

The agitated children were managed by administering fentanyl $1.0 \mu \mathrm{g} / \mathrm{kg}$ with at least a 10-minute interval between

Table 2. The Modified Aldrete Postanesthesia Score

\begin{tabular}{lc}
\hline \multicolumn{1}{c}{ Criteria } & Point value \\
\hline Oxygenation & 2 \\
SpO2 $>92 \%$ on room air & 1 \\
SpO2 $>90 \%$ on oxygen & 0 \\
SpO2 $<90 \%$ on oxygen & \\
Respiration & 2 \\
Breathes deeply and coughs freely & 1 \\
Dyspnoeic, shallow or limited breathing & 0 \\
Apnoea & \\
Circulation & 2 \\
Blood pressure \pm 20 mmHg of normal & 1 \\
Blood pressure $\pm 20-50$ mmHg of normal & 0 \\
Blood pressure more than \pm 50 mmHg of normal & \\
Consciousness & 2 \\
Fully awake & 1 \\
Aousable on calling & 0 \\
Not responsive & \\
Activity & 2 \\
Moves all extremities & 1 \\
Moves two extremities & 0 \\
No movement & \\
\hline
\end{tabular}

each dose. The drug was discontinued as soon as the symptoms had disappeared.

Modified Aldrete postanesthesia score (Table 2) was adopted as the discharge criteria according to which a score $>9$ is needed for discharge. Patients who fulfilled the discharge criteria were transferred to the ward unit and the delivery time was recorded.

Statistical analysis was performed using SPSS 12.0 (SPSS Inc., Chicago, IL, USA). Continuous variables, such as age, height, weight, duration of anesthesia, duration of surgery, duration of extubation after the end of surgery, duration of the PACU stay, and modified CHEOPS were confirmed to follow a normal distribution. Among the variables, duration of extubation, which was reported as the mean $\pm \mathrm{SD}$, was analyzed using oneway ANOVA, whereas the other continuous variables were examined using a Kruskal-Wallis test. The categorical variables were compared using a Chi-square test for gender and a Fisher's exact test for the ASA, postoperative nausea/vomiting scores, and Emergence Agitation scores. A P value $<0.05$ was considered significant.

\section{Results}

Of the 93 patients, one out of each group experienced laryngospasm after extubation and were excluded. No sideeffects such as hallucination or nightmare were observed in the groups administered with ketamine. There were no significant differences in both the time span from the end of surgery until the extubation time and the time span from the arrival at the PACU to the transfer to the ward unit between the three groups. Postoperative pain scores showed significant differences between the three groups, where the scores were significantly different not only between the control group and K0.25 group,

Table 3. Modified CHEOPS (Children's Hospital of Eastern Ontario Pain Scale)

\begin{tabular}{llll}
\hline \multicolumn{1}{c}{ Score } & \multicolumn{1}{c}{0} & \multicolumn{1}{c}{1} & \multicolumn{1}{c}{2} \\
\hline Cry & No Cry & Crying, moaning & Scream \\
Facial & Smiling & Composed & Grimace \\
Verbal & Positive & None or other complaints & Pain complaint \\
Torso & Neutral & Shifting, tense, upright & Restrained \\
Legs & Neutral & Kicks, squirm, drawn up & Restrained \\
\hline
\end{tabular}

Table 4. Extubation time, Delivery Time, and PONV (Postoperative Nausea, Vomiting)

\begin{tabular}{lccc}
\hline \multicolumn{1}{c}{ Group } & $\mathrm{C}(\mathrm{n}=30)$ & $\mathrm{K} 0.25(\mathrm{n}=30)$ & $\mathrm{K} 0.5(\mathrm{n}=30)$ \\
\hline Extubation time (min) & $10.24 \pm 3.66$ & $11.28 \pm 3.19$ & $10.69 \pm 3.34$ \\
Delivery time (min) & $40.00(40.00,50.00)$ & $40.00(40.00,50.00)$ & $40.00(36.50,50.00)$ \\
PONV $(1: 2: 3: 4)$ & $24: 4: 2: 0$ & $26: 0: 4: 0$ & $23: 1: 6: 0$ \\
\hline
\end{tabular}

Values of extubation time are mean \pm SD. Values of delivery time are median $(25 \%, 75 \%)$. There are no significant differences among the three groups. PONV scale : 1 = none, 2 = retching, 3 = one episode of vomit, $4=$ multiple episode of vomit. 
Table 5. Pain Score (Modified CHEOPS), and Agitation Score

\begin{tabular}{lccc}
\hline \multicolumn{1}{c}{ Group } & $\mathrm{C}(\mathrm{n}=30)$ & $\mathrm{K} 0.25(\mathrm{n}=30)$ & $\mathrm{K} 0.5(\mathrm{n}=30)$ \\
\hline Modified CHEOPS & $8.00(6.00,9.00)$ & $3.00(2.00,6.00)^{*}$ & $2.00(1.00,2.00)^{*,+}$ \\
Agitation score $(1: 2: 3: 4)$ & $1: 5: 14: 10$ & $11: 9: 8: 2^{*}$ & $17: 11: 2: 0^{*}$ \\
\hline
\end{tabular}

Values of modified CHEOPS are median $(25 \%, 75 \%)$. Agitation score $: 1=$ asleep, $2=$ awake and calm, $3=$ agitated but consolable, $4=$ severely agitated and inconsolable. ${ }^{*} \mathrm{P}<0.05$ compared with the Group $\mathrm{C},{ }^{\dagger} \mathrm{P}<0.05$ compared with the Group K0.25.

between the control group and K0.5 group, but also between the K0.25 and K0.5 group (Table 3). No significant differences in the incidence of nausea and vomiting were observed between the groups (Table 4).

As for Emergence Agitation scores, there existed significant differences between the control and K0.25 group, and between the control and K0.5 group, whereas no significant differences were detected between the K0.25 and K0.5 group (Table 5).

\section{Discussion}

Sevoflurane is an inhalational anesthetic that is used widely as pediatric or outpatient anesthesia due to its excellence in hemodynamic stability and low blood solubility, which allows rapid induction and emergence from general anesthesia, and allows control of the depth of anesthesia. However, when sevoflurane is used alone, it is associated with a higher incidence of emergence agitation (EA) in children. The rapid removal of residual anesthetics due to the low blood solubility of sevoflurane has been suggested to cause EA in some patients [1,5-10]. In addition, a variety of other explanations have been proposed for the etiology of EA. These include the lack of a young child's ability to adapt to sudden changes due to an unfamiliar environment after awakening, immature neurological development, anxiety from being separated from their parents, increased pain sensation, sympathetic hyperactivation, etc [5,10-12].

EA is characterized by self-limiting aggressive agitation that develops in the early phase of awakening from anesthesia at the end of surgery. The term 'Delirium' is sometimes used to describe such a state [10] but other terms, such as 'agitation' or 'excitation', are usually preferred because it is not feasible to evaluate a young child's psychological state during emergence. EA can be dangerous to patients, particularly to young children. Patients suffering from EA may harm themselves and dislodge drains or catheters, which will affect the results of surgery. They may inflict a bodily injury on their parents [caregivers] or cause a paranoiac accident, which makes the management and monitoring of patients at the PACU difficult [13-15].

Furthermore, it is difficult to differentiate between pain and EA in young patients because they are poor at expressing their pain and because EA mostly disappears within 15 minutes [4].
Therefore, it is possible to misunderstand self-limiting EA as pain and administer analgesics, such as fentanyl, which creates confusion because of its similarity to the time of pain being controlled.

There have been many attempts to reduce the incidence of EA by propofol [16,17], fentanyl [18], ketamine [3,4,19], ketolorac [20], nalbuphine [19], etc., but the etiology and preventive treatments of EA are still unclear.

Ketamine is a $N$-methyl-D-aspartate (NMDA) receptor antagonist with a strong analgesic effect at a less than anesthesia-inducting dose [21]. It does not cause respiratory depression at small doses $(<1 \mathrm{mg} / \mathrm{kg})$, and has little effect on the heart rate and blood pressure [22]. The incidence of arousal responses, such as nightmares or hallucinations, which restrains the clinical employment of ketamine, is $5-30 \%$ at large doses of ketamine [23]. However, the incidence is lower at small doses ( $<1 \mathrm{mg} / \mathrm{kg}$ ) compared to opioids [24]. This study did not encounter a case of hemodynamic instability, or postoperative hallucinations or nightmares.

Kawaraguch et al. [25] reported that the administration of ketamine $1 \mathrm{mg} / \mathrm{kg}$ after the induction of anesthesia and the instillation of ketamine $1 \mathrm{mg} / \mathrm{kg} / \mathrm{hr}$ during surgery in pediatric strabismus surgery succeeded in decreasing EA. Abu-Shahwan et al. [4] showed that an intravenous injection of ketamine 0.25 $\mathrm{mg} / \mathrm{kg}, 10 \mathrm{~min}$ before the end of surgery in a dental operation for young children under general anesthesia with sevoflurane decreased the incidence of EA without a delay in recovery. Dalens et al. [19] reported that the intravenous administration of ketamine $0.25 \mathrm{mg} / \mathrm{kg}$ or nalbuphine $0.1 \mathrm{mg} / \mathrm{kg}$ in general anesthesia with sevoflurane for young children undergoing magnetic resonance imaging was effective in preventing the incidence of EA without delaying awakening or recovery. The present study was designed to compare the effects of small doses of ketamine, $0.25 \mathrm{mg} / \mathrm{kg}$ and $0.5 \mathrm{mg} / \mathrm{kg}$, which are hemodynamically stable and have fewer side effects, such as hallucinations or nightmares, on EA and postoperative pain. In contrast to the control group, the K0.25 and K0.5 groups showed a decrease in the incidence of EA and a significant decrease in pain intensity at the PACU. Compared to the K0.25 group, the K0.5 group showed a significant decrease in pain intensity at the PACU but not in the incidence of EA, which suggests that an increase in the ketamine dose was effective in analgesic action, 
whereas the increase in dose did not affect the incidence of EA. Therefore, it is believed that besides pain, a variety of other causes should make a contribution to the incidence of EA. Hence, a dose of ketamine $0.25 \mathrm{mg} / \mathrm{kg}$ alone administered 10 min before the end of surgery would reduce the incidence of EA due to the combined analgesic and sedative action of ketamine. Although ketamine $0.5 \mathrm{mg} / \mathrm{kg}$ did not further decrease the incidence of EA compared to ketamine $0.25 \mathrm{mg} / \mathrm{kg}$, a dose of $0.5 \mathrm{mg} / \mathrm{kg}$ is recommended for clinical treatment because of the significant analgesic effect at the PACU. Regarding the mechanism of ketamine in reducing the incidence of EA, Lerman et al. [26] suggested that ketamine inhibits the central nervous system effect in ether-linked inhalation anesthetics, which is responsible for increasing the incidence EA after anesthesia with sevoflurane.

The bronchodilating characteristics of ketamine was expected to be effective in preventing the severity of laryngospasm after extubation in young children undergoing an adenotonsillectomy but one from each group experienced laryngospasm after extubation and were excluded. Compared to the control group, the K0.25 and K0.5 groups did not affect the delay in extubation or recovery time, or increase the incidence of nausea and vomiting.

This study had some limitations. First, the three groups did not demonstrate any significant differences in terms of age, even though the study was conducted on children, ranging in age from 2 to 14 years, and was not restricted to preschool children particularly vulnerable to EA. Second, the reason the adenotonsillectomy i.e. severe inflammation in the pharyngeal tonsil or problematic snoring, was not examined, even though postoperative pain, which is greater in case of severe inflammation in the pharyngeal tonsil, can be another variable in the pain scores and the incidence of EA. Further study giving more consideration to such limitations will be needed for more reliable research results.

In conclusion, a dose of $0.25 \mathrm{mg} / \mathrm{kg}$ or $0.5 \mathrm{mg} / \mathrm{kg}$ of ketamine, administered intravenously $10 \mathrm{~min}$ before the end of surgery, successfully reduced the incidence of EA without any particular side-effects or delays in recovery. Although the administration of ketamine $0.5 \mathrm{mg} / \mathrm{kg}$ did not decrease the incidence of EA more than that of ketamine $0.25 \mathrm{mg} / \mathrm{kg}$, ketamine $0.5 \mathrm{mg} / \mathrm{kg}$ had significant analgesic effects on postoperative pain at the PACU. Therefore, $0.5 \mathrm{mg} / \mathrm{kg}$ ketamine, which decreases the incidence of EA and has postoperative analgesic effect, is recommended as the appropriate dose.

\section{References}

1. Cravero J, Surgenor S, Whalen K. Emergence agitation in paediatric patients after sevoflurane anaesthesia and no surgery: a comparison with halothane. Paediatr Anaesth 2000; 10: 419-24.

2. Sandner-Kiesling A, Schwarz G, Vicenzi M, Fall A, James RL, Ebner F, et al. Side-effects after inhalational anaesthesia for paediatric cerebral magnetic resonance imaging. Paediatr Anaesth 2002; 12: 429-37.

3. Kararmaz A, Kaya S, Turhanoglu S, Ozyilmaz MA. Oral ketamine premedication can prevent emergence agitation in children after desflurane anesthesia. Paediatr Anaesth 2004; 14: 477-82.

4. Abu-Shahwan I, Chowdary K. Ketamine is effective in decreasing the incidence of emergence agitation in children undergoing dental repair under sevoflurane general anesthesia. Paediatr Anaesth 2007; 17: 846-50.

5. Aono J, Ueda W, Mamiya K, Takimoto E, Manabe M. Greater incidence of delirium during recovery from sevoflurane anesthesia in preschool boys. Anesthesiology 1997; 87: 1298-300.

6. Johannesson GP, Florén M, Lindahl SG. Sevoflurane for ENT surgery in children: a comparison with halothane. Acta Anaesthesiol Scand 1995; 39: 546-50.

7. Davis PJ, Greenberg JA, Gendelman M, Fertal K. Recovery characteristics of sevoflurane and halothane in preschool-aged children undergoing bilateral myringotomy and pressure equalization tube insertion. Anesth Analg 1999; 88: 34-8.

8. Walker SM, Haugen RD, Richards A. A comparison of sevoflurane with halothane for paediatric day case surgery. Anaesth Intensive Care 1997; 25: 643-9.

9. Welborn LG, Hannallah RS, Norden JM, Ruttimann UE, Callan CM. Comparison of emergence and recovery characteristics of sevoflurane, desflurane, and halothane in pediatric ambulatory patients. Anesth Analg 1996; 83: 917-20.

10. Uezono S, Goto T, Terui K, Ichinose F, Ishguro Y, Nakata Y, et al. Emergence agitation after sevoflurane versus propofol in pediatric patients. Anesth Analg 2000; 91: 563- 6.

11. Davis PJ, Cohen IT, McGowan FX Jr, Latta K. Recovery characteristics of desflurane versus halothane for maintenance of anesthesia in pediatric ambulatory patients. Anesthesiology 1994; 80: 298-302.

12. Ebert TJ, Muzi M. Sympathetic hyperactivity during desflurane anesthesia in healthy volunteers. A comparison with isoflurane. Anesthesiology 1993; 79: 444-53.

13. Voepel-Lewis T, Malviya S, Tait AR. A prospective cohort study of emergence agitation in the pediatric postanesthesia care unit. Anesth Analg 2003; 96: 1625-30.

14. Veyckemans F. Excitation phenomena during sevoflurane anesthesia in children. Curr Opin Anaesthesiol 2001; 14: 339-43.

15. Wells LT, Rasch DK. Emergence 'delirium after sevoflurane anesthesia: a paranoid delusion? Anesth Analg 1999; 88: 1308-10.

16. Usher AG, Kearney RA, Tsui BC. Propofol total intravenous anesthesia for MRI in children. Paediatr Anaesth 2005; 15: 23-8.

17. Tsui BC, Wagner A, Usher AG, Cave DA, Tang C. Combined propofol and remifentanil intravenous anesthesia for pediatric patients undergoing magnetic resonance imaging. Paediatr Anaesth 2005; 15: 397-401.

18. Cohen IT, Hannallah RS, Hummer KA. The incidence of emergence agitation associated with Desflurane Anesthesia in Children is reduced by fentanyl. Anesth Analg 2001; 93: 88-91.

19. Dalens BJ, Pinard AM, Létourneau DR, Albert NT, Truchon RJ. 
Prevention of emergence agitation after sevoflurane anesthesia for pediatric cerebral magnetic resonance imaging by small doses of ketamine or nalbuphine administered just before discontinuing anesthesia. Anesth Analg 2006; 102: 1056-61.

20. Keidan I, Zaslansky R, Eviatar E, Segal S, Sarfaty SM. Intraoperative ketolorac is an effective substitute for fentanyl in children undergoing outpatient adenotonsillectomy. Paediatr Anaesth 2004; 14: 318-23.

21. Warncke T, Stubhaug A, Jørum E. Ketamine, an NMDA receptor antagonist, suppresses spatial and temporal properties of burninduced secondary hyperalgesia in man: a double blind, cross-over comparison with morphine and placebo. Pain 1997; 72: 99-106.

22. Jahangir SM, Islam F, Aziz L. Ketamine infusion for postoperative analgesia in asthmatics: a comparison with intermittent meperi- dine. Anesth Analg 1993; 76: 45-9.

23. White PF, Way WL, Trevor AJ. Ketamine-its pharmacology and therapeutic uses. Anesthesiology 1982; 56: 119-36.

24. Dich-Nielsen JO, Svendsen LB, Berthelsen P. Intramuscular lowdose ketamine versus pethidine for postoperative pain treatment after thoracic surgery. Acta Anaesthesiol Scand 1992; 36: 583-7.

25. Kawaraguchi Y, Miyamoto Y, Fukumitsu K, Taniguchi A, Hirao O, Kitamura S, et al. The effect of ketamine on reducing postoperative agitation after sevoflurane anesthesia in pediatric strabismus surgery. Masui 2002; 51: 1343-8.

26. Lerman J, Davis PJ, Welborn LG, Orr RJ, Rabb M, Carpenter R, et al. Induction, recovery, and safety characteristics of sevoflurane in children undergoing ambulatory surgery. A comparison with halothane. Anesthesiology 1996; 84: 1332-40. 